\title{
Higienização das mãos: utilização de uma câmara escura luminescente como recurso didático na prevenção da Covid-19
}

\section{Hand hygienization: use of a luminescent camera obscura as a didactic resource in Covid-19 prevention}

\author{
${ }^{1}$ Leonan Guerra leonan.guerra@yahoo.com.br \\ ${ }^{2}$ Fernando Vasconcellos de Oliveira \\ ${ }^{3}$ Vanessa Candito \\ ${ }^{4}$ Maria Rosa Chitolina
}

\begin{abstract}
RESUMO
O conhecimento em higiene consiste na adoção de medidas de proteção, com o intuito de promover a saúde e evitar formas de contaminação por doenças infectocontagiosas. O objetivo desse estudo foi relatar uma experiência pedagógica, sobre o uso de uma câmara escura luminescente por meio de uma atividade lúdica, visando a discussão e à reflexão da importância de higienizar corretamente as mãos para evitar o contágio do Coronavírus e outros micro-organismos infecciosos. Essa atividade foi desenvolvida em uma escola da rede privada, no município de Santa Maria/RS, durante o mês de março de 2020. Os sujeitos dessa atividade foram 26 escolares, pertencentes aos $3^{\circ}$ e $4^{\circ}$ Anos Iniciais. Foi construída uma câmara escura utilizando uma caixa de papelão e uma lâmpada de luz ultravioleta, além do gel fluorescente feito com o refil de caneta marca texto misturado com gel de cabelo. Para a coleta de dados utilizou-se o diário de bordo do professor, observação participante e uma roda de conversa. Os resultados obtidos evidenciam que a câmara escura é uma proposta inovadora no ensino de ciências, e na prevenção da Covid-19, pois proporcionou a construção do conhecimento, principalmente quando se objetiva a mudança de hábitos de higiene. Percebeu-se que a utilização da câmara escura, como material didático lúdico foi eficaz, pois as crianças tornaram-se multiplicadoras de informações corretas sobre a higienização das mãos ajudando a evitar o contágio do Coronavírus.
\end{abstract}

Palavras-chave: Coronavírus. Ensino. Lavagem das mãos.

\section{ABSTRACT}

Knowledge in hygiene consists of adopting protective measures, in order to promote health and prevent forms of contamination by infectious diseases. The objective of this study was to report a pedagogical experience, about the use of a luminescent camera obscura through a ludic activity, aiming at discussing and reflecting on the importance of properly cleaning your hands to prevent the spread of Coronavirus and other infectious microorganisms. This activity was developed in a private school in the city of Santa Maria (RS), during the month of March 2020. The subjects of this activity were 26 students, belonging to the 3rd and 4th years of elementar school. A camera obscura was built using a cardboard box and an ultraviolet light bulb, in addition to the fluorescent gel made with the highlighter pen refill mixed with hair gel. For data collection, the teacher's logbook, participant observation and a conversation wheel were used. The results obtained show that the darkroom is an innovative proposal in science education, and in the prevention of Covid-19, as it provided the construction of knowledge, especially when the aim is to change hygiene habits. It was noticed that the use of the camera obscura as a ludic teaching material was effective, as children became multipliers of correct information about hand hygiene, helping to prevent the spread of the Coronavirus.

Keywords: Coronavirus. Teaching. Handwashing.

\footnotetext{
1 Doutorando em Educação em Ciências: química da vida e saúde, Universidade Federal do Rio Grande do Sul.

2 Doutorando em Educação em Ciências: química da vida e saúde, Universidade Federal de Santa Maria.

Mestranda em Educação em Ciências: química da vida e saúde, Universidade Federal do Rio Grande do Sul.

Professora adjunta da Universidade Federal de Santa Maria.
} 


\section{INTRODUÇÃO}

O ensino de Ciências para os Anos Iniciais, do Ensino Fundamental apresenta algumas particularidades, entre elas o compromisso com o desenvolvimento do letramento científico, que envolve a capacidade de compreender e interpretar o mundo (BRASIL, 2018). Neste contexto, é de suma importância que atividades diferenciadas sejam desenvolvidas no ambiente escolar a fim de intensificar a aprendizagem dos escolares.

Para Santos e Coutinho (2020, p.42480), “A escola, é considerada a responsável pelos os direitos das crianças e adolescentes e pelo atendimento às suas demandas educacionais, sociais e emocionais”. Sendo assim, Tavares e Rocha (2006) trazem a necessidade de estabelecer um espaço na escola onde seja suscitado o debate para maior compreensão da relação entre saúde e seus determinantes mais gerais, possibilitando processos de aprendizagem permanente para os envolvidos. Além disso, a escola é responsável pelo processo de socialização dos escolares, e pelo desenvolvimento da aprendizagem (SANTOS; COUTINHO, 2020).

Deste modo, os escolares poderão formar atitudes e valores, em benefício de sua saúde e da saúde dos outros do seu convívio. Sendo assim, a Organização Mundial da Saúde indicou como uma das medidas simples para combater efetivamente a COVID-19 é intensificar os hábitos saudáveis de higiene, como lavar as mãos corretamente (WHO, 2020). Essas ações devem ser intensificadas nas famílias, levando em consideração os diferentes estilos de vida por meio de condutas simples e da participação de todos (TAVARES; ROCHA, 2006).

Delizoicov, Angotti, Pernambuco (2011) destacam que por meio do diálogo, entre educandos e educadores, é possível a construção de conhecimentos sobre o mundo e o local em que se vive. "Ao promover o diálogo, pode-se interpretar que, ao mesmo tempo que o aluno questiona e o professor contextualiza sobre o saber do aluno, observa-se uma forma diferenciada no processo de ensino e aprendizagem” (BARRETO et al. 2020, p. 57).

Desta forma, o ato de problematizar é a obtenção do conhecimento prévio do educando, não apenas para saber que ele existe, e sim para formular problemas que possam levá-los a compreensão e construção do conhecimento científico (DELIZOICOV; ANGOTTI; PERNAMBUCO, 2009). Entretanto é muito importante salientar que é o professor quem vai direcionar e organizar as discussões dos estudantes durante a atividade, não no sentido de dar respostas prontas, mas para questionar as interpretações assumidas pelos educandos (GEHLEN; MALDANER; DELIZOICOV, 2012). Com essa perspectiva o professor precisa estar consciente do seu papel em sala de aula, deixando fluir as discussões sobre as necessidades e conflitos vivenciados pelos sujeitos (SILVA, 2004).

Neste contexto, baseado nos Pressupostos Freireanos de educação, discute-se a relevância da problematização e dialogicidade no ensino, com vistas a formação de sujeitos críticos. Para Paulo Freire, o diálogo assume um papel fundamental da prática pedagógica, não simplesmente para ensinar os conteúdos, mas para despertar e favorecer a formação de uma consciência crítica (FREIRE, 2014). O autor ainda ressalta que, na prática problematizadora “[...] os educandos desenvolvem o seu poder de captação e de compreensão do mundo, em suas relações com ele, não mais como uma realidade estática, mas como uma realidade em transformação, em processo" (FREIRE, 1983, p. 82).

Freire (2001) descreve a necessidade de o professor ter bom senso ao desenvolver suas práticas pedagógicas para atingir mais facilmente a autonomia dos educandos. Levando os pressupostos do autor em consideração, acredita-se que a utilização de atividades lúdicas é sempre interessante nas atividades pedagógicas, pois torna-se uma metodologia acessível.

Nesse contexto, objetivo desse estudo é relatar uma experiência pedagógica, sobre o uso de uma câmara escura luminescente por meio de uma atividade lúdica, visando a discussão e à reflexão da importância de higienizar corretamente as mãos, para evitar o contágio do Coronavírus e outros micro-organismos infecciosos. 


\section{MATERIAIS E MÉTODOS}

Nesse estudo, empregou-se a metodologia de natureza qualitativa. De acordo com Minayo (2001), a pesquisa qualitativa trabalha com o universo de significados, motivos, aspirações, crenças, valores e atitudes, o que corresponde a um espaço mais profundo das relações, dos processos e dos fenômenos que não podem ser reduzidos à operacionalização de variáveis. Além disso, Bogdan e Biklen (1994, p. 47-51), a investigação qualitativa tem na sua essência, cinco características: (1) a fonte direta dos dados é o ambiente natural e o investigador é o principal agente na recolha desses mesmos dados; (2) os dados que o investigador recolhe são essencialmente de caráter descritivo; (3) os investigadores que utilizam metodologias qualitativas interessam-se mais pelo processo em si do que propriamente pelos resultados; (4) a análise dos dados é feita de forma indutiva; e (5) o investigador interessa-se, acima de tudo, por tentar compreender o significado que os participantes atribuem às suas experiências.

Essa experiência intitulada “Sr. Bactéria”, foi desenvolvida no laboratório de ciências, em uma escola da rede privada, no município de Santa Maria, região central do estado do Rio Grande do Sul, durante o mês de março de 2020. Participaram dessa experiência, 26 escolares pertencentes aos $3^{\circ}$ e $4^{\circ}$ Anos do Ensino Fundamental I (Anos Iniciais da Educação Básica). Esses educandos fazem parte do Clube de Ciências, onde são realizadas atividades semanais, no período vespertino (contraturno das aulas regulares), sendo ofertado como atividade extracurricular da instituição escolar.

Para a coleta de dados utilizou-se o diário de bordo do professor, observação participante e uma roda de conversa. A experiência trata-se de uma discussão focada em tópicos específicos na qual os participantes são incentivados a manifestarem opiniões sobre o tema de interesse (IERVOLINO; PELICIONI, 2001). Assim, os estudantes conseguem trocar relatos sobre suas experiências individuais com o grupo, criando um ambiente conhecimentos emergentes.

Segundo Melo e Cruz (2014, p. 31) as opiniões expressas nessas Rodas de Conversa são "falas” sobre determinados temas discutidos pelos participantes sem a preocupação com o estabelecimento de um consenso, podendo as opiniões convergirem ou divergirem, provocando o debate e a polêmica em torno do tema Coronavírus. Consideramos o diário de bordo um instrumento de trabalho do docente, pois nele podem ser relatados elementos empíricos e reflexivos sobre os acontecimentos da classe, os interesses e motivações das ações realizadas, o nível de acessibilidade das informações, a organização do espaço, a distribuição do tempo e tipo de tarefas realizadas (WENDLING; CAMPOS, 2013). Conforme Soldati (2005), o diário de bordo se apresenta como uma ferramenta simples, de fácil aplicação, adaptável em todos os espaços e a todas as observações, inclusive no espaço escolar.

Quanto aos aspectos éticos, este projeto de pesquisa foi revisado e aprovado pelo Comitê de Ética e Pesquisa da Universidade Federal de Santa Maria (UFSM), com o número CAAE 58113416.0.0000.5346.

\section{ELABORAÇÃO DA ATIVIDADE}

Para a realização da atividade, intitulada "Sr. Bactéria”, foi construída uma câmara escura. Decidiu-se optar por esse nome, justamente pelo fato dessa atividade ter sido desenvolvida na semana que em as escolas tinham iminência de interromper as aulas presenciais, para evitar um possível contágio do Coronavírus, e muitos estudantes serem crianças, as instituições tinham receio de participar de qualquer atividade que tratasse dessa temática. Então para aproximar e estimular as crianças da proposta, a atividade foi preparada com vários desenhos coloridos de microrganismos, deixando-a assim com um visual mais lúdico.

A câmara escura para a atividade lúdica pode ser observada na figura 01. Para a construção dessa foram utilizados os seguintes materiais: uma caixa de papelão medindo $30 \mathrm{~cm}$ de largura x $40 \mathrm{~cm}$ de comprimento x $30 \mathrm{~cm}$ 
de altura; tinta guache preta; estilete; e desenhos de micro-organismos para decorar a parte externa. Para criar o efeito mais lúdico da caixa, foi usada uma lâmpada de luz negra, também referida como luz UV-A, que emite luz ultravioleta de onda longa (UV-A), e um suporte para encaixar a lâmpada na tomada de energia elétrica. Já para a produção do líquido fluorescente foi utilizada uma caneta “marca texto” (atóxica) na cor amarela, $20 \mathrm{ml}$ de água e um recipiente com $100 \mathrm{ml}$ de gel para cabelo, incolor e sem álcool (de composição química conhecida).

Primeiramente, com auxílio de um estilete foram recortados dois círculos na parte lateral da caixa, pois foi através desses círculos que os alunos colocaram as mãos dentro dela. Logo após foi recortado um retângulo na parte superior do objeto, que serviu para os estudantes observarem as mãos dentro dele. Essa foi totalmente pintada de preto por dentro e por fora, a fim de destacar a luminescência, um fenômeno de emissão de luz por parte das substâncias presentes na tinta marca texto, nesse caso, submetidas a luz negra. Em seguida através de um pequeno orifício feito do outro lado da caixa em que os círculos não tinham sido recortados, foi acoplado a lâmpada de luz negra no soquete e esse foi firmemente encaixado na caixa.

Figura 01 - Câmara escura que foi utilizada durante a atividade.

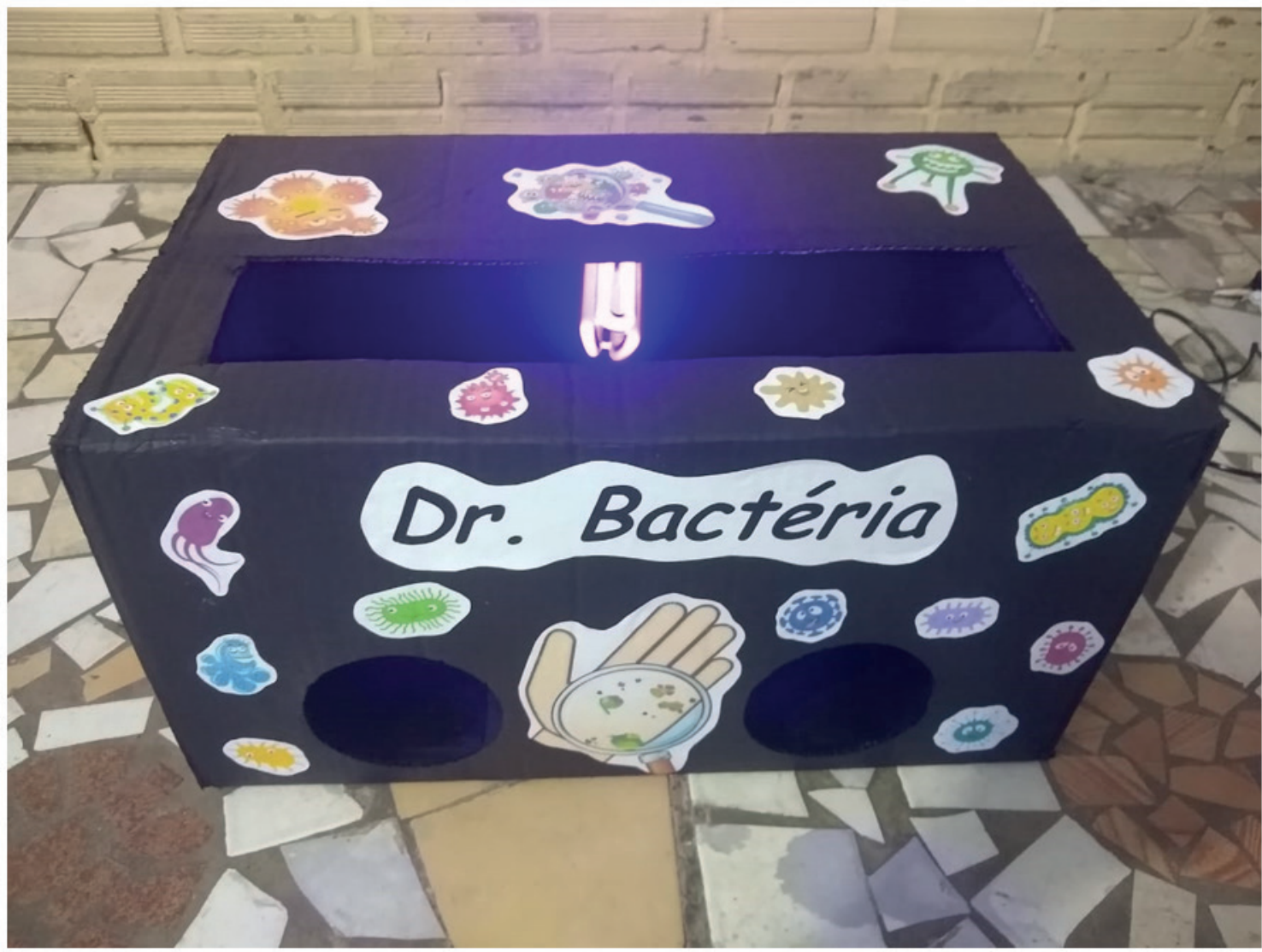

Fonte: Autoria própria (2020).

Após essa etapa, foi produzido o gel fluorescente retirando o refil da caneta marca texto. Esse foi cortado em pequenos pedaços e então imersos dentro de um recipiente contendo $20 \mathrm{ml}$ de água. Em seguida a água já tingida, foi misturada ao gel de cabelo e então o gel fluorescente ficou pronto (Figura 02). 
Figura 02 - Materiais utilizados para a produção do gel fluorescente.

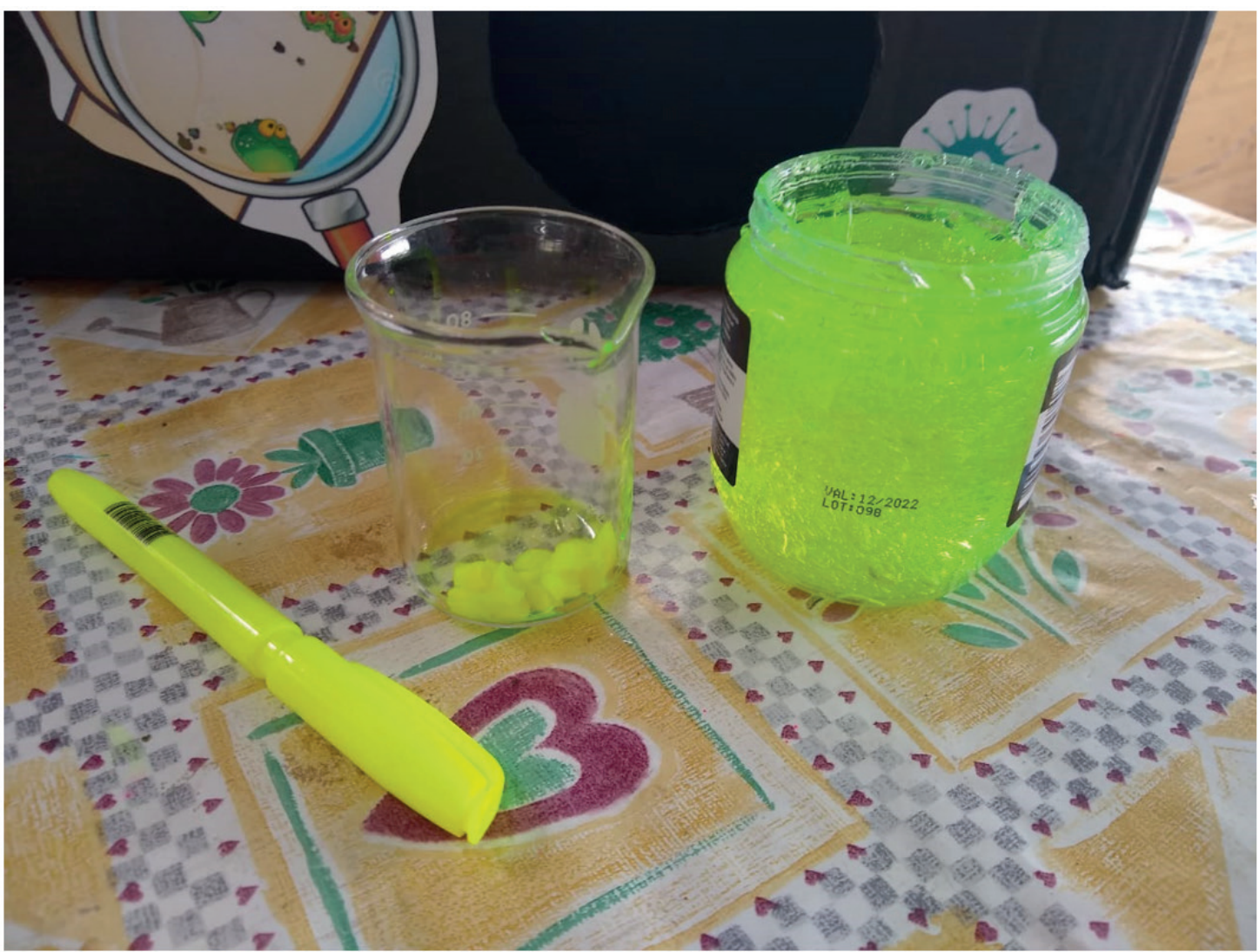

Fonte: Autoria própria (2020).

Após o término da confecção da câmara escura e do gel fluorescente, foi desenvolvido um guia de estudo para auxiliar os escolares na higienização das mãos, assim poderiam acompanhar o desenvolvimento da atividade, sem a necessidade de anotar as principais informações. Esse guia apresentava uma pequena introdução sobre a importância da higiene das mãos para evitar o contágio do Coronavírus, e uma figura contendo todos os passos de como as mãos deveriam ser lavadas corretamente. Além do desenho de uma mão com o número um, e também espaços ao lado desse desenho com os números dois, três e quatro, para serem desenhadas as mãos dos outros integrantes do grupo. Com a finalidade de mostrar a contaminação que pode ocorrer quando uma pessoa cumprimenta a outra sem ter higienizado corretamente as mãos.

\section{DESENVOLVIMENTO DA ATIVIDADE}

Segundo Cabrera (2007, p. 30), “[...] o lúdico cria descontração, favorece o envolvimento e o fluxo, condições essas necessárias para estabelecer o clima para a aprendizagem na busca de resultados positivos”. Neste sentido, a atividade realizada propiciou um momento lúdico, na qual os estudantes puderam adquirir conhecimentos, e relatar experiências.

Os estudantes adentraram no laboratório de ciências ansiosos para saberem qual seria a temática desenvolvida, já que os temas de cada atividade do Clube de Ciências, somente são revelados no início de cada aula, despertando assim a curiosidade, que ficou ainda mais aguçada quando observaram a câmara escura e não sabiam ao certo como utilizar. 
Após a organização nas bancadas do laboratório, deu-se início as discussões em torno da pandemia que estava acontecendo no mundo, e o que cada um deles poderia fazer para evitar a contaminação pelo Coronavírus. Assim, o conteúdo apresentado na aula foi adaptado diante do que estava sendo observado no momento atual da sociedade. Nesse momento, vários estudantes responderam que poderiam lavar as mãos, mas não sabiam explicar corretamente como deveria ser feito esse procedimento. Sá-Silva et al. (2010), reiteram que o conhecimento em higiene consiste na adoção de medidas de proteção, com o intuito de promover a saúde e evitar formas de contaminação por doenças infectocontagiosas, ou seja, a higienização das mãos é uma das formas de evitar o contágio pelo Coronavírus, desde que essa seja feita de maneira correta.

Foi então que o professor explicou como ia ser desenvolvida a atividade utilizando o gel fluorescente e a câmara escura. Após essa explicação, os educandos foram divididos em grupos, e somente um estudante de cada grupo recebeu o gele fluorescente nas mãos. O educando com o gel nas mãos cumprimentava um colega do seu grupo, e esse cumprimentava o próximo e assim sucessivamente, até o quarto e último estudante de cada grupo. Esse momento foi tomado por uma grande discussão mediada pelo professor pois as crianças não enxergavam nada nas mãos, apenas sentiam que essas estavam um pouco molhadas devido ao gel que nas mãos ficava incolor. O último integrante de cada grupo por apresentar menos gel nas mãos, não percebia nenhuma mudança. Após essa etapa cada grupo foi levado até a câmara escura para colocar as mãos no lugar indicado da caixa e observar o contágio dos quatro integrantes do seu grupo com muita atenção, pois cada estudante deveria desenhar a sua mão e a dos colegas nos números de um a quatro indicados no guia de estudo.

Esse momento da aula foi de extrema euforia, pois quando cada estudante colocava as mãos na câmara escura saia impressionado com o que tinha visto nas suas mãos (Figura 03).

Figura 03 - Estudantes observando as mãos contaminadas na câmara escura.
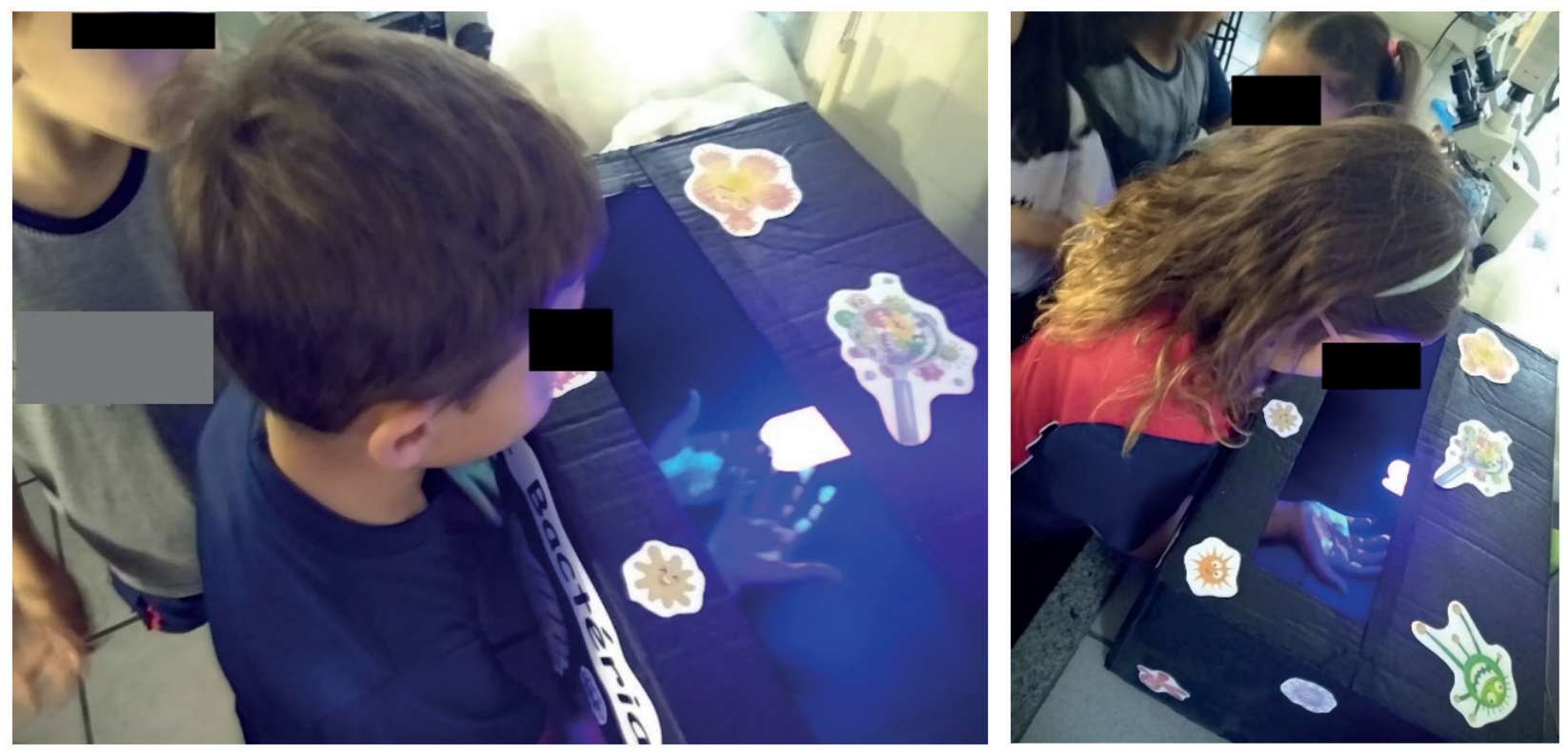

Fonte: Autoria própria (2020).

Nas palavras de Freire, o educador deve exercer a prática docente para que os educandos tenham autonomia para aprender sem pressões (FREIRE, 2010). Assim, a prática docente deve procurar aguçar a curiosidade dos estudantes, por meio de pesquisas e na troca de saberes, facilitando o ensino/aprendizagem por meio das atividades lúdicas, que interagem com os objetivos propostos da atividade. Cavalcanti e Soares (2009) destacam que o uso de atividades lúdicas permite avaliar ou diagnosticar dificuldades conceituais em determinados conteúdos, possibilitando intercâmbio de ideias, bem como corrigir falhas evidenciadas. Exatamente como aconte- 
ceu, quando os estudantes participavam da atividade enquanto utilizavam a câmara escura. Assim, depois que todos os grupos já tinham inserido as mãos na câmara escura, foi iniciada uma nova discussão sobre a importância de higienizar corretamente as mãos para evitar o contágio principalmente do Coronavírus caso algum colega estivesse infectado. Segundo a cartilha higienização das mãos em serviços de saúde (BRASIL, 2007), a limpeza das mãos é considerada a ação isolada mais importante à prevenção e o controle de infecções em serviços de saúde, sendo nesse momento de pandemia causada pelo Coronavírus de extrema importância.

Os escolares comentaram que tinham visto na mídia, reportagens falando sobre a transmissão do vírus, mas não imaginavam que um simples aperto de mão, mesmo com a "aparência limpa” pudesse transmitir o vírus. Nesse momento, o professor abriu uma nova discussão quando perguntou quem já tinha lavado as mãos naquela tarde antes de ir para a aula. A grande maioria respondeu que tinha lavado as mãos apenas depois de ter ido ao banheiro, mas que tinham feito o lanche e depois brincado durante o recreio com os colegas sem se preocupar em lavar as mãos. No entanto, segundo Brasil (2008, p. 28), “Conservar as mãos sempre limpas, as unhas aparadas e evitar colocar a mão na boca”, pode evitar o contágio de doenças, devendo as mãos serem higienizadas com frequência.

Após essa discussão cada estudante desenhou as suas mãos e a dos colegas nos guias de estudo, pintando nos desenhos a contaminação que tinham observado, quando colocadas na câmara escura (Figura 04).

Figura 04 - Estudantes fazendo os desenhos nos guias de estudo das mãos contaminadas.
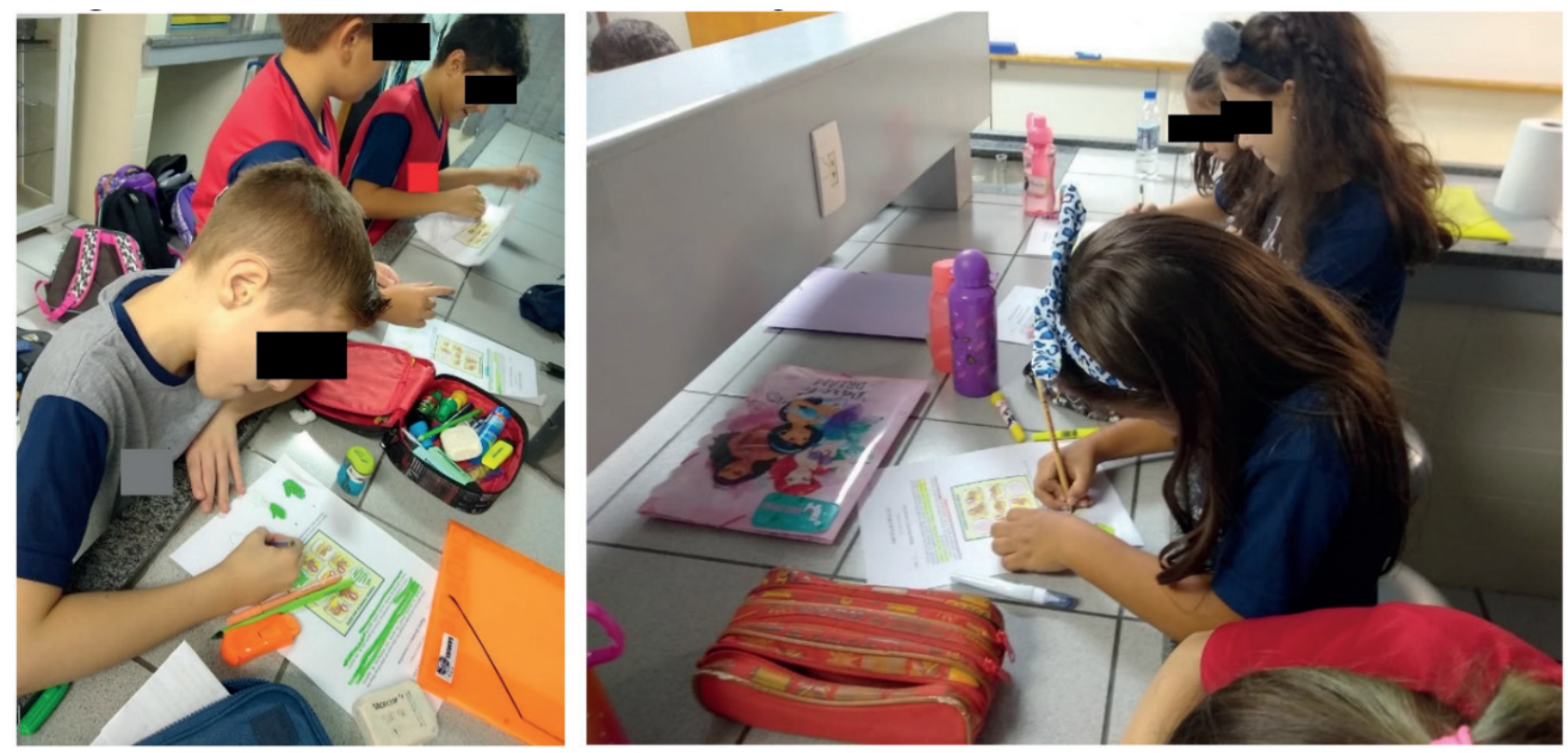

Fonte: Autoria própria (2020).

Na etapa seguinte o professor ensinou detalhadamente como deveriam ser higienizadas as mãos. Cada grupo se dirigiu as pias do laboratório, e então iniciou-se o processo de higienização utilizando para isso água e sabão. O professor seguiu o procedimento de higiene de mãos, conforme as práticas seguras de higiene das mãos, disponibilizada pela Agência Nacional de Vigilância Sanitária, e explicou cada etapa e observando como os estudantes estavam fazendo. Sendo assim, Silva e Leda (2012) enfatiza que medidas simples, porém não menos importantes, como a lavagem das mãos e de alimentos com água e sabão comum, é eficaz no combate das infecções intestinais, além de ser fundamental para evitar a propagação do Coronavírus e outras doenças infectocontagiosas.

Após todos terem lavado e secado as suas mãos com papel toalha, esses foram encaminhados novamente para a câmara escura para observarem se as mãos estavam verdadeiramente limpas. Foi então, que introduziu-se uma nova discussão, pois muitos estudantes ainda estavam com manchas nas mãos o que significava que não 
tinham lavado corretamente. Esses então, lavaram novamente as mãos e após a observação na câmara escura perceberam que essas estavam totalmente limpas. Sendo assim, o educador necessita assumir seu papel efetivo de modificador social, capaz de propor mudanças que despertem no aluno o desejo de aprender e buscar conhecimentos novos, além de dar-lhe condições de adquiri-lo de forma agradável e prazerosa, explorando situações condizentes com a realidade do cotidiano (FEREIRA et al. 2012).

Além de toda a explicação oferecida pelo professor na hora da atividade, os estudantes ainda podiam observar as gravuras no guia de estudo que explicavam todos os passos do processo de higienização das mãos. De acordo com Ferreira e Andrade (2005), a valorização da higienização das mãos, se apresenta como uma importante prática educativa, sendo considerada uma das mais simples formas de prevenção do Coronavírus, em tempos de pandemia de Covid-19, devendo ser trabalhadas de forma efetiva nas escolas.

Foi possível perceber que alguns educandos comentaram que iriam mostrar para a docente titular da turma, o guia de estudo para incentivá-la a desenvolver alguma atividade semelhante com toda a turma. Sendo assim, os professores podem agir como agentes multiplicadores de temas relevantes, principalmente por ser a escola um ambiente onde a criança passa a maior parte de seu tempo (MOREIRA et al., 2011). Pois como afirmam Kruschewsky et. al. (2008) a educação em saúde tem como objetivo a prevenção das doenças, buscando a mudança de comportamento através do despertar de uma consciência crítica, além de construir nas pessoas um conceito acerca de hábitos saudáveis. Sendo muito importante abordar já nos anos inicias do ensino fundamental práticas educativas que busquem a saúde, dando ênfase para a prevenção de doenças que podem ser evitadas com a higienização correta das mãos.

Assim, a prática propiciou refletir sobre a importância de trabalhar em aulas, tema nas quais fazem parte do cotidiano do educando, dando significado e promovendo uma leitura crítica da realidade. Seguindo os pressupostos de Paulo Freire, que ensinar não pode ser um puro processo, de transferência de conhecimento do educador ao educando. O estudo crítico corresponde um ensino, como uma forma de compreender e de realizar a leitura da palavra e a leitura do mundo, leitura do contexto (FREIRE, 2001).

Outra situação inusitada aconteceu no final da aula, quando os pais foram buscar as crianças, essas estavam eufóricas com a atividade e explicaram de maneira correta para seus pais como deveria ser o processo de higienização das mãos. Além disso, alguns pais também queriam passar o gel nas mãos e colocar na câmara escura para observar o resultado. Minnaert e Freitas (2010) ressaltam que as práticas higiênicas refletem hábitos que se instituem como códigos socioculturais e as mudanças podem significar mais que a alteração de práticas comportamentais. Essas práticas podem ter início nas atividades escolares com a participação indiretamente dos pais quando em casa os filhos repassam as informações das atividades desenvolvidas na escola, ou diretamente quando por exemplo, os pais participam juntamente com as crianças das atividades que são desenvolvidas no espaço escolar.

Como destacado por Muenchen e Delizoicov (2012), a problematização, possibilita relacionar aspectos importantes da realidade do educando, a partir da discussão, investigação, diálogo. Neste sentido a atividade permitiu uma atividade lúdica, e possibilitou aos educandos, discutir, participar, dialogar, problematizar, avaliar e transformar o seu conhecimento, por meio de uma temática atual, na qual foi identificada em uma situação significativa relacionadas ao cotidiano dos escolares.

\section{CONSIDERAÇÕES FINAIS}

Os resultados obtidos evidenciam que a câmara escura, por meio do fenômeno de luminescência, é uma proposta inovadora no ensino de ciências, desde que os estudantes reflitam suas ações durante a atividade e saibam como utilizá-las de maneira correta no seu cotidiano. Além disso, a utilização da câmara escura, como instrumento de prevenção da Covid-19, coloca para as crianças participantes, a capacidade de aplicar no coti- 
diano de seus lares e em outros ambientes as medidas de higienização das mãos, recomendadas pelos órgãos mundiais de saúde.

Percebeu-se ao longo da atividade que a motivação dos educandos, e também dos pais no final da aula, é indispensável para que seja possível a construção do conhecimento, principalmente quando se objetiva a mudança de hábitos de higiene.

A atividade proporcionou à turma formação acerca da prática de higienização das mãos através da participação ativa dos estudantes já que esses se mostraram motivados e curiosos durante todo a aula. Nesse sentido, percebeu-se que a utilização da câmara escura, como material didático lúdico foi eficaz, pois o público alvo que eram crianças, e essas tornaram-se multiplicadoras de informações corretas sobre a higienização das mãos ajudando a evitar o contágio do Coronavírus.

\section{REFERÊNCIAS}

BARRETO, P. G.; SALES, J. P. A.; DE ARAÚJO, L. C.; MAIA, P. H. D.; LOBO, M. P. Ensino e aprendizagem de eletrostática utilizando os três momentos pedagógicos de Delizoicov e Angotti. Revista do Professor de Física, v. 4, n. 2, p. 55-65, 26 ago. 2020.

BOGDAN, R. C.; BIKLEN, S. K. Investigação qualitativa em educação: uma introdução à teoria e aos métodos. Portugal: Porto Editora, 1994.

BRASIL. Agência Nacional de Vigilância Sanitária. Higienização das mãos em serviços de saúde. Brasília: Anvisa, 2007.

BRASIL. Módulo 12: higiene, segurança e educação. Brasília: Universidade de Brasília/MEC, 2008.

BRASIL. Base Nacional Comum Curricular. Brasília: MEC, 2018. Disponível em: http://basenacionalcomum. mec.gov.br/. Acesso em: 25 set. 2020.

CABRERA, W. B. A Ludicidade para o Ensino Médio na disciplina de biologia. 2007. Dissertação (Mestrado em Ensino de Ciências e Educação Matemática) - Universidade Estadual de Londrina, Londrina, 2007.

CAVALCANTI, E. L. D.; SOARES, M. H. F. B. O RPG como estratégia de problematização e avaliação do conhecimento químico. Revista Electrónica de Enseñanza de las Ciencias, n. 8, p. 255-280, 2009.

DELIZOiCOV, D.; ANGOTTI, J. A. P.; PERnAMBUCO, M. M. C. A. Ensino de ciências: fundamentos e métodos. 3. ed. São Paulo: Cortez, 2009.

DELIZOICOV, D.; ANGOTTI, J. A.; PERNAMBUCO, M. M. Ensino de ciências: fundamentos e métodos. 4.ed. São Paulo: Cortez, 2011.

FERREIRA, G. R.; ANDRADE, C. F. S. Alguns aspectos socioeconômicos relacionados a parasitoses intestinais e avaliação de uma intervenção educativa em escolares de Estiva Gerbi, SP. Revista da Sociedade Brasileira de Medicina Tropical, v. 38, n. 5, p. 402-405, set-out, 2005.

FERREIRA, E. A.; GODOI, T. R. A; SILVA, L. G. M; SILVA, T. P; ALBUQUERQUE, A. V. Aplicação de jogos lúdicos para o ensino de química: auxilio nas aulas sobre tabela periódica. In: Encontro Nacional de Educação, Ciência e Tecnologia, 1., 2012, Campina Grande. Anais [...]. Campinha Grande: UEPB, 2012.

FREIRE, P. Carta de Paulo Freire aos professores. Estudos avançados, São Paulo, v. 15, n. 42, p. 259-268, 2001. 
FREIRE, P. Pedagogia do oprimido. Rio de Janeiro: Paz e Terra, 1983.

FREIRE, P. Pedagogia do Oprimido. 50. ed. Rio de Janeiro: Paz e Terra, 2014.

GEHLEN, S. T.; MALDANER, O. A.; DELIZOICOV, D. Momentos pedagógicos e as etapas da situação de estudo: complementaridades e contribuições para a educação em ciências. Ciência \& Educação, Bauru, v. 18, n. 1, p. 1-22, 2012.

IERVOLINO, S. A.; PELICIONI, M. C. F. A utilização do grupo focal como metodologia qualitativa na promoção da saúde. Revista Escola de Enfermagem, v. 35, n. 2, p.115-21, jun. 2001.

KRUSCHEWSKY, E. J.; KRUSCHEWSKY, M. E.; CARDOSO, J. P. Experiências pedagógicas de educação popular em saúde: a pedagogia tradicional versus a problematizadora. Revista de Saúde.com, v. 4, n. 2, p.160176, 2008.

MELO, M. C. H.; CRUZ, G. Roda de conversa: uma proposta metodológica para a construção de um espaço de diálogo no ensino médio. Imagens da Educação, v. 2, n. 4, 2014. Disponível em: http://periodicos.uem.br/ojs/ index.php/ImagensEduc/ article/view/22222/pdf_5. Acesso em: 21 maio 2020.

MINAYO, M. C. de S. Pesquisa social: teoria, método e criatividade. Petrópolis: 2001, Vozes.

MINNAERT, A. C. S. T.; FREITAS, M. C. S. Práticas de higiene em uma feira livre da cidade de Salvador (BA). Ciência \& Saúde Coletiva, v. 15, p. 1607-1614, 2010.

MOREIRA, B. L. da R. et al. Educação sexual na escola: implicações para a práxis dos adultos de referência a partir das dúvidas e curiosidades dos adolescentes. Revista Electrónica de Enseñanza de las Ciencias, v. 10, n. 1, p. 64-83, 2011.

MUENCHEN, C.; DELIZOICOV, D. A construção de um processo didático-pedagógico dialógico: aspectos epistemológicos. Revista Ensaio, Belo Horizonte, v. 14, n. 3, p. 199-215, 2012.

SÁ-SILVA, J. R. et al. Escola, educação em saúde e representações sociais: problematizando as parasitoses intestinais. Pesquisa em Foco, v. 18, n. 1, p. 82-95, 2010.

SANTOS, J. V dos ; COUTINHO, D. J. G. A contribuição da família no contexto escolar. Braz. J. of Develop., Curitiba, v. 6, n. 7, p. 42478-42498, jul. 2020.

SILVA, C. S. Escola Promotora de Saúde: uma visão crítica da Saúde Escolar. In: Sociedade Brasileira de Pediatria - Departamento Científico de Saúde Escolar. Cadernos de Escolas Promotoras de Saúde - I, p. 14-20, 1997.

SILVA, A. F. G. A construção do currículo na perspectiva popular crítica: das falas significativas às práticas contextualizadas. 2004. Tese (Doutorado em Educação) - Pontifícia Universidade Católica de São Paulo, São Paulo, 2004.

SILVA T. V; LEDA L. R. Intervenções educativas sobre parasitoses intestinais: aplicação de um jogo para alunos do ensino fundamental. Saúde \& Amb. Rev., Duque de Caxias, v. 7, n. 2, p. 23-07, jul-dez, 2012.

SOLDATI, M. Capoeira: prevention et mediation educative auprès de jeunes en situation de risque au Brésil. Genova: Universidade de Genova, Memória de Licenças, 2005.

TAVARES, M. F. L.; ROCHA, R. M. Promoção da Saúde e a Prática de Atividade Física em Escolas de Manguinhos - Rio de Janeiro. In: Ministério da Saúde. Escolas promotoras de saúde: experiências do Brasil. Brasília: Ministério da Saúde/Organização Pan-Americana da Saúde, n. 6, 2006. 
WENDLING, C. M.; CAMPOS, S. D. Análise dos Registros em Diário de Bordo sobre Alfabetização. In: SEMINÁRIO REGIONAL DE FORMAÇÃO CONTINUADA DE PROFESSORES E MOSTRA DE EXPERIÊNCIAS E VIVÊNCIAS PEDAGÓGICAS, 3., 2013, Presidente Prudente. Anais [...]. Presidente Prudente, 2013.

WORLD HEALTH ORGANIZATION (2020). Coronavirus disease (COVID-19) situation report-102. (2020). Disponível em: https://www.who.int/docs/default-source/coronaviruse/situation-reports/20200501-covid-19sitrep.pdf?sfvrsn=742f4a18_2. Acesso em: 25 set. 2020. 